\title{
TIPOLOGÍA DE VISITANTE TURÍSTICO Y SATISFACCIÓN DE LA EXPERIENCIA TURÍSTICA EN SANTIAGO DE COMPOSTELA*
}

\author{
Fernando Almeida García
}

\begin{abstract}
RESUMEN
En este artículo se pretende identificar los distintos tipos de flujos turísticos que afectan a Santiago de Compostela y su relación con la presión turística que soporta. Esta ciudad es buen ejemplo de lo que acontece en numerosos destinos turísticos culturales. Por otro lado, se analiza el grado de satisfacción que presenta el turista que visita la ciudad y su percepción de pérdida de calidad turística.
\end{abstract}

\begin{abstract}
In this paper differents types of tourist flows in Saint James of Compostela are identified and connect with tourist pressure. This Town is a good example that in the other tourist destination happens. In the other hand, tourist satisfaction degree that enjoys the Town and their perception about tourist quality loosing.

* Este estudio forma parte de la convocatoria de Ayudas para Proyectos de Investigación sobre materias turísticas del Programa de Ciencias Sociales del Plan Gallego de Investigación, Desarrollo e Innovación Tecnológica, 2004/05. Dirección Xeral de Turismo, Xunta de Galicia.

\section{INTRODUCCIÓN}

Las ciudades históricas y los destinos turísticos en general se enfrentan a diversos problemas y retos que dificultan su desarrollo y el propio futuro de éstos. Uno de estos problemas es que pueden "morir de éxito". Los núcleos turísticos tienden a atraer con fuerza al turista y al visitante pero una de las consecuencias de esa "fuerza física" es alterar el normal funcionamiento de la ciudad o el espacio turístico.
\end{abstract}


La ciudad funciona como un organismo vivo que tiene la virtud de estar constantemente recomponiendo el tejido y absorbiendo los impactos que le provocan sus moradores y sus visitantes. Estos impactos varían en relación al volumen de visitantes, tamaño de la ciudad o núcleo, peso del turismo en la economía local, configuración urbana y territorial, madurez del destino, etc.

En el caso de las ciudades históricas, se ha observado que éstas han tenido que ir adaptándose a numerosos cambios, que ha supuesto pasar de ser tejidos residenciales y/o administrativos para convertirse en espacios de ocio y contemplación. Esta situación es extrapolable a la mayor parte de las ciudades europeas con un importante patrimonio histórico.

La presión provocada por los visitantes sobre el espacio urbano y sobre los residentes genera toda una serie de problemas, que en la actualidad es uno de los mayores retos al que se enfrenta la ciudad histórica. De forma física, la zona más presionada coincide con un área bien acotada como es el casco histórico y de forma más concreta en torno a los hitos urbanos: catedral, palacio, plaza, museo, etc. Aunque la tensión turística se puede repartir por toda la ciudad, afecta de una forma más evidente a los cascos históricos.

Por otro lado, es importante conocer cómo el uso masivo de los recursos y productos turísticos puede afectar a la calidad de la experiencia turística. Para ello es necesario conocer el comportamiento de los flujos turísticos y las características de la oferta en relación con la capacidad de acogida.

En el caso de estudio, Santiago de Compostela es una ciudad turística que se ha consolidado como uno de los destinos de turismo cultural más importantes de España. El notable patrimonio monumental y cultural, junto con la larga tradición de peregrinaje hace de Santiago una ciudad conocida en Europa.

El éxito turístico de la ciudad ha hecho que el flujo de visitantes haya aumentado de forma constante. Como referencia y teniendo en cuenta la especial situación en un Año Santo, Santiago recibió cerca de tres millones de excursionistas y un millón de turistas en el 2004, en una ciudad de algo menos de 100.000 habitantes.

Este proceso de crecimiento de la actividad turística es un hecho común a las ciudades Patrimonio de la Humanidad de España y a otras ciudades europeas turísticas (De la Calle, 2002). Con ello se quiere destacar que aunque este estudio se centra en Santiago de Compostela, es fenómeno que también acontece en otras ciudades como Toledo, Granada o Venecia.

El progresivo aumento de visitantes en Santiago de Compostela, ha generado un conjunto de problemas o en términos económicos deseconomías, que dificultan el posicionamiento de la ciudad entre los grandes destinos culturales de Europa. Esto obedece al fuerte efecto ancla de la Catedral y su entorno próximo y la especial configuración física de la ciudad, que tiende a 
concentrar a los visitantes en torno a un espacio físico reducido. A estos factores espaciales habría que añadir los temporales, que incrementan aún más la concentración de los visitantes. La congestión es evidente en verano y especialmente en los Años Santos, como el del 2004.

Estos hechos nos obligan a una reflexión sobre cómo gestionar los flujos de los visitantes para conseguir que la experiencia de la visita a Santiago mantenga su calidad, cómo conseguir que la utilización de los recursos turísticos se haga de una forma sostenible y cómo favorecer que la explotación de unos recursos públicos generen la mayor calidad de vida posible para la población local.

Este artículo analiza el funcionamiento básico de los flujos turísticos dentro de la ciudad y la experiencia del visitante en relación con la experiencia turística. Ésta se apoya en la evaluación de las características básicas de la oferta y en el análisis de la percepción de la masificación del destino turístico.

\section{ANÁlisis DE LOS FLUJOS TURÍSTICOS EN SANTIAgo DE COMPOSTELA}

\subsection{Introducción}

Una ciudad que se ha nacido en torno a la acogida de visitantes, es normal que haya adaptado parte de su fisonomía alrededor de este hecho; es por ello por lo que la recepción y ocupación de los espacios públicos de Compostela por turistas y visitantes es una actividad asumida como propia por la ciudad.

A lo largo del tiempo los peregrinos y visitantes fueron creando una serie de itinerarios y rituales básicos en torno a la ciudad. Esta se ocupó activamente creando todo un conjunto de iglesias, monasterios, albergues y hospitales para estos singulares turistas.

De esta forma se fue consolidando todo un importante itinerario en torno al Camino Francés, con entrada desde la Rúa de San Pedro, hacia la Porta do Camiño y desde allí hacia la Catedral.

En la creación y, por supuesto, en la gestión de los flujos turísticos juega un papel fundamental la meta final del turista, visitante o peregrino que llega a Santiago: es decir la Catedral y sus espacios anejos.

No hay una experiencia satisfactoria sin la visita a la Catedral de Santiago y sus plazas, independientemente de las expectativas desarrolladas antes de la llegada a la ciudad. Este hecho generará una fuerte congestión en todas las inmediaciones a este monumento.

La masificación o utilización excesiva de un recurso turístico es algo habitual en las ciudades históricas, ya que un espacio o monumento es el que 
suele funcionar como reclamo y elemento diferenciador del destino. Es por ello por lo que tal situación obliga a que todos los visitantes que llegan a una ciudad quieran ver y disfrutar de dicho recurso para que la visita sea satisfactoria. Una visita a Granada sin la Alhambra o a Londres sin el Big Beng no es completa. De hecho se suele fusionar hito y destino turístico. Este ahorro de información, simplifica en exceso la riqueza y los matices que pueden aportar los destinos turísticos e incrementa la presión sobre los hitos.

Esta situación se intensifica en el caso de Santiago de Compostela, pues la tradición de peregrinaje obliga en buena parte a dirigirse a un punto específico, como es la visita a la tumba del Apóstol, con una magnifica escenografía que invita a ello.

Así pues, a pesar de la gran variedad de recursos patrimoniales que a lo largo del tiempo ha ido acumulando Santiago de Compostela, la visita de la ciudad, en la mayor parte de las ocasiones se centra en un espacio bastante reducido, (unas 2,5 a 3 has.) más pequeño que el que ocupa el casco histórico protegido (27,5 has. aprox.). La zona de máxima ocupación está formada por un rectángulo entre la avenida Xoán XXIII y la Praza de Galicia que está cortado en su parte central por la catedral y sus plazas adyacentes.

\subsection{Tipología de los flujos de los visitantes}

La entrada en la ciudad por parte del turista o visitante se suele hacer desde de tres puntos: Porta do Camino, Porta da Mamoa (Praza do Toural) y Avenida de Xoán XXIII. Desde allí se dirigen hacia el punto de encuentro que es la Catedral y las plazas anexas (Obradorio, Quintana y Platerías). Cada una de estas tres entradas permite distinguir tres tipologías de visitante.

\section{A. El Excursionista. Avenida de Xoán XXIII}

El excursionismo tiene una gran importancia y tradición en Santiago de Compostela. La ciudad tradicionalmente es parada obligada de los circuitos turísticos que se dirigen al noroeste de la Península. El notable número de excursionistas explica la existencia de una infraestructura de acogida específica para éstos: la Dársena de Xoán XXIII. Es una forma muy cómoda de acercarse a la Catedral, destino obligado de estos excursionistas.

Si bien este fenómeno, en términos globales parece que se va atenuando, según los datos proporcionados por la propia Dársena, sigue siendo una actividad muy notable, especialmente en los Años Santos. En el 2004 arribaron a la Dársena más de 900.000 excursionistas y unos 2.000.000 llegaron en vehículo propio, según información de los aparcamientos de la ciudad (Turismo de Santiago, 2005). 


\section{ENTRADAS DE VIAJEROS EN LA DÁRSENA DE XOÁN XXIII}

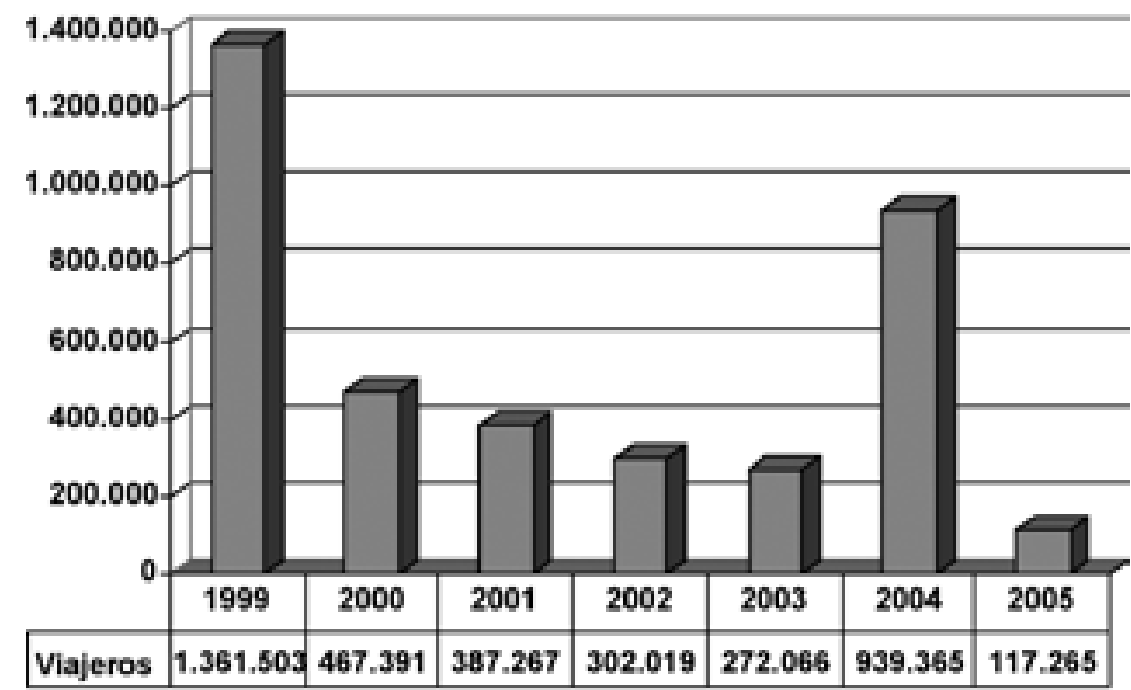

Fuente: Turismo de Santiago.

La relación entre presión turística y excursionismo es evidente, pues este segmento que tiene una estancia cortísima, en muchos casos su visita es de horas, es el que tensiona más los espacios hitos turísticos y los servicios públicos. La rentabilidad económica para la ciudad suele ser escasa, aunque en términos turísticos un excursionista es un potencial turista.

El recorrido habitual de los grupos turísticos es desde la Avenida Xoán XXIII hacia la Rúa de San Francisco y desde ahí al Obradorio y la propia Catedral. La duración media del recorrido de los grupos es de unas cinco horas. El grupo turístico, ya sea por la escasez de tiempo, ya sea por la actividad gregaria, raramente realiza una incursión lejana del casco histórico. Este tipo de turista es el que menos se aleja de la catedral.

\section{B. El turista. Praza de Galicia}

Además del excursionista, Santiago recibe un importante flujo de turistas, más de un millón en el 2004. De éstos, unos 615.000 alojados en hoteles y hostales y unos 500.000 en otro tipo de alojamientos (Ciudad de Vacaciones, albergues, etc.).

Este tipo de visitante tiene una estancia media más elevada que el excursionista (2,12 días en el 2004). Esta estancia es más prolongada que la de las ciudades del entorno (1,83 días en La Coruña, 1,77 en Vigo) y de las Ciuda- 
des Patrimonio de la Humanidad españolas (Ávila 1,49 días en 2004, 1,6 en Cáceres, 1,49 Córdoba, 1,5 Segovia, etc.) y que de las otras grandes ciudades monumentales (1,94 días en Sevilla y 1,73 en Granada).

El turista suele acercarse al casco histórico a través de la Praza de Galicia y desde ahí se adentra en el casco antiguo. La mayor estancia media permite que sus recorridos se difuminen por el casco histórico y no únicamente en torno a la Catedral y que la presión sea algo menor. Además el alojamiento se reparte entre el casco histórico, el Ensanche y las afueras de la Ciudad.

En los últimos seis años se observa una tendencia a aumentar los turistas, teniendo en cuenta los picos de máximos de 1999 (Año Santo) y de 2000 (Capital Europea de la Cultura).

\section{EVOLUCIÓN DE LA DEMANDA TURÍSTICA EN SANTIAGO DE COMPOSTELA}

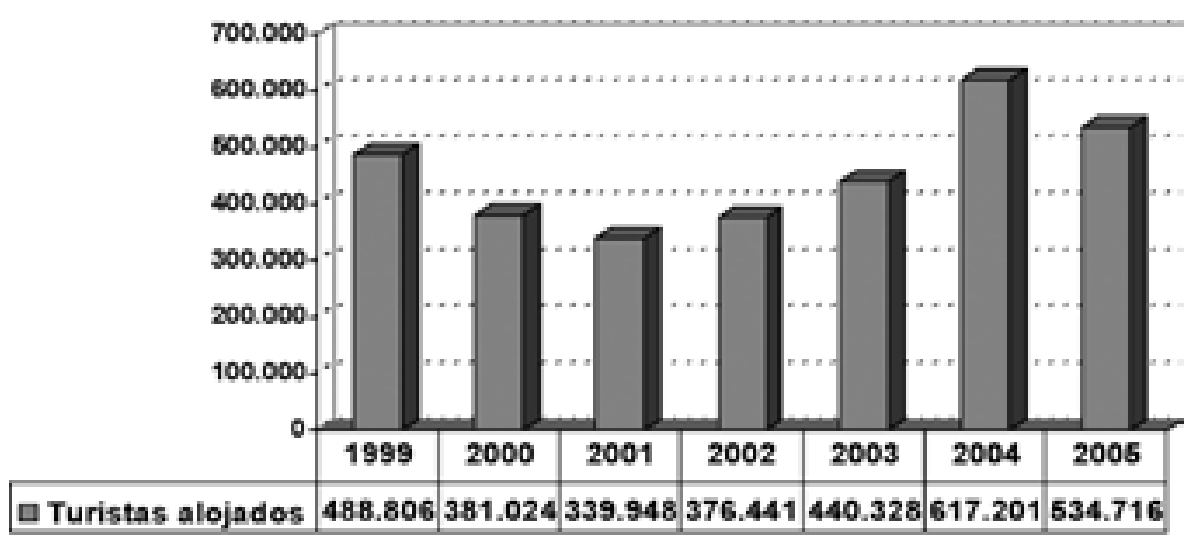

Fuente: INE.

\section{El peregrino. Porta do Camiño}

Esta puerta de entrada es la que utilizan principalmente los peregrinos, que es una modalidad de visitante turístico que tiene una particular importancia en Santiago de Compostela. De hecho, es el peregrinaje la razón de la propia existencia de la ciudad.

La entrada Este de la ciudad se hace desde la cercana rúa de San Pedro cuya prolongación nos lleva hasta San Lázaro y desde allí al Monte do Gozo, última etapa tradicional antes de la llegada a Santiago. Desde la Porta do Camiño el peregrino se adentra en el casco histórico y desde allí alcanza la Catedral. 
La estancia media del peregrino en Santiago no es muy elevada (1,5 días). Una vez llegado a su destino final no suele permanecer mucho tiempo. La estancia está en directa relación al tiempo dedicado al camino y la capacidad adquisitiva.

El número de peregrinos ha ido aumentando considerablemente en los últimos años. Ha pasado de ser un número casi simbólico en los años 80 (2.5003000) hasta alcanzar los casi 180.000 en el año 2004. Hay que señalar que estas cifras son las que están reguladas por la Oficina de Peregrino que es la que concede la "Compostelana", certificado de haber realizado la peregrinación. El peregrinaje a la ciudad es una actividad en constante aumento, a un ritmo de un 10\% anual, que se dispara en los años santos (1993, 1999 y 2004).

\section{EVOLUCIÓN DE LA DEMANDA TURÍSTICA EN SANTIAGO DE COMPOSTELA}

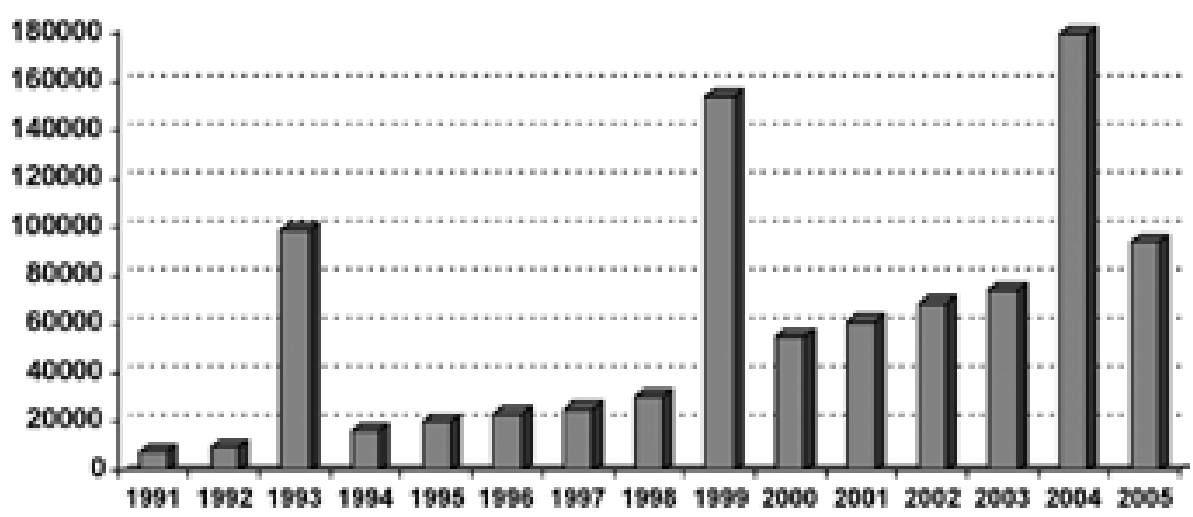

Fuente: Oficina del Peregrino, Santiago de Compostela. 
FERNANDO ALMEIDA GARCÍA

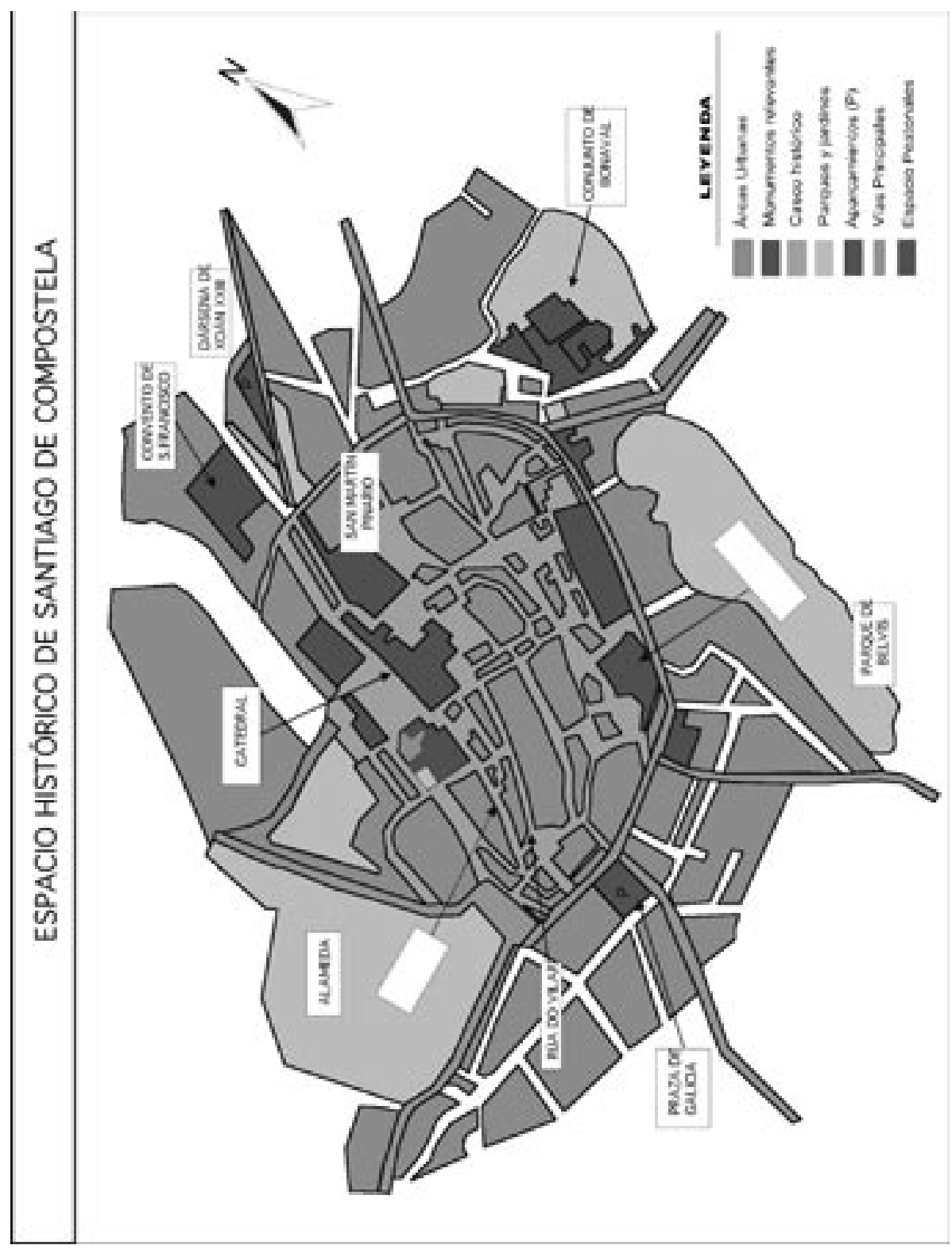




\section{INDICADORES BÁSICOS DE PRESIÓN TURÍSTICA}

\section{Estimación de la capacidad de carga social percibida por los turistas}

\subsection{Introducción}

Dentro del marco de creciente expansión del turismo cultural, la afluencia masiva de visitantes a determinados elementos del patrimonio histórico-cultural, obliga a gestionar el turismo desde unos parámetros de sostenibilidad, limitación necesaria para la protección del patrimonio y para el mantenimiento de calidad necesaria de la experiencia turística. Desde esta óptica resulta absolutamente necesario conocer los límites de un recurso para su explotación turística, es decir conocer su capacidad de acogida.

Así que la capacidad de carga o acogida de un espacio respecto a su utilización turística es uno de los conceptos centrales de la gestión de la propia actividad y de los impactos que ésta puede generar. No es un fin en sí mismo, sino un medio útil para mejorar las condiciones de la experiencia del visitante y para orientar las decisiones que se han de tomar al respecto.

La capacidad de carga o acogida es un concepto que surgió a partir de necesidades operativas fundamentalmente relacionadas con la gestión de los flujos de visitantes en espacios naturales protegidos. Con posterioridad se empezaron a incorporar otros aspectos a la hora de delimitar la capacidad de acogida del espacio. Estos aspectos, que estaban relacionados con el uso del espacio por parte de los visitantes y con la actividad de los gestores, se consideran modificadores de la capacidad de carga que imponen inicialmente las características físicas del espacio. En este sentido se introdujeron dos parámetros básicos: la identificación de niveles de uso aceptables e inaceptables y la búsqueda de la calidad de la experiencia del visitante.

En esencia, el concepto de capacidad de acogida lleva implícito la idea de restricción o límite más allá del cual la explotación turística de un recurso es insostenible por perjudicial. Existen varias definiciones de capacidad de acogida en función de la naturaleza de ese límite: límite físico, límite percibido socialmente o limitación de naturaleza económica. A partir de esas definiciones se puede hablar de distintas dimensiones de la capacidad de carga: la capacidad de carga "física", la capacidad de carga "social" y la capacidad de carga "económica" del espacio.

- La capacidad de acogida física de un espacio se relaciona con dos elementos; por una parte con la capacidad del sistema para ofrecer servicios turísticos, es decir con la capacidad de acogida máxima de las infraestructuras de servicios, y por otro con la capacidad del espa- 
cio para absorber visitantes en relación a su fragilidad física o medioambiental. Esta dimensión viene determinada en el caso de Santiago, por una parte por la extensión y el nivel de adecuación de los espacios visitables "alternativos" orientados a la acogida del visitante y a la atenuación de los tiempos de espera para visitar algunos monumentos como la Catedral, y por otra parte, por las exigencias de conservación de los espacios más frágiles.

- La capacidad de acogida social o perceptual está determinada por el nivel de tolerancia de la población residente frente a los visitantes y por la propia experiencia de los visitantes. Es decir, desde este punto de vista, la capacidad de acogida de un territorio es el número máximo de visitantes que éste puede recibir sin que decline irreversiblemente la calidad de la experiencia del visitante medida a partir de la congestión y saturación (fuentes del deterioro de la experiencia turística). Este enfoque plantea problemas operativos ya que la medición de la capacidad de acogida en función de la experiencia turística depende de la actitud de los visitantes, parámetro en suma variable que puede verse modificado a partir de simples mejoras en la gestión de los flujos turísticos, por las expectativas generadas en campañas de promoción, por la información recibida sobre las condiciones de la visita y también por el grado de conocimiento acerca del monumento. En conjunto, variar los umbrales de capacidad de acogida social de un espacio resulta más fácil que modificar los límites que vienen determinados por las características físicas del propio espacio.

- Por último, la dimensión económica de la capacidad de acogida está relacionada con el límite más allá del cual la función turística perturba otras actividades locales.

En resumen, la capacidad de acogida está estrechamente ligada con las densidades de uso del espacio e implica restricciones de utilización o explotación de los recursos basadas en unos límites que vienen determinados ya sea por las características físicas del propio espacio, ya sea por las exigencias de mantener la calidad de la experiencia del visitante. Operativamente son, por tanto, varios los factores que deben considerarse para determinar el límite o umbral máximo de "explotación turística":

- Factores medioambientales o físicos relacionados con la dimensión del conjunto y el espacio utilizable, así como la fragilidad y exigencias de conservación de los recursos patrimoniales.

- Factores sociales relacionados con las pautas de comportamiento de los visitantes, su opinión y la naturaleza de su experiencia estética. 
- Los procedimientos de gestión que tienen que ver con el diseño de itinerarios que canalicen y distribuyan el uso del espacio, la facilitación de servicios de información e interpretación, el incremento de la resistencia de los recursos utilizados y la adecuación de espacios e instalaciones "alternativos" y de servicio al visitante.

Desde este punto de vista, la capacidad de carga de un conjunto monumental como Santiago de Compostela, viene determinada fundamentalmente por dos aspectos clave: las exigencias de la conservación del conjunto monumental y la calidad de la experiencia estética y el confort del visitante, relacionada con factores como la ausencia de ruido, la ausencia de congestión visual, la atenuación de los tiempos de espera y la correcta interpretación del monumento, así como la creación de otros espacios escénicos.

En todo caso es preciso tener siempre en cuenta que la capacidad de carga o acogida de un espacio respecto a su utilización turística no es un fin en si mismo, sino un medio para conocer el recurso, orientar las decisiones que se han de tomar en la gestión turística.

\subsection{Visitantes y capacidad de carga social}

Los gestores y planificadores del espacio turístico son responsables de las demandas y necesidades de los turistas. Es necesario, entonces, que se conozcan y diagnostiquen los requerimientos de los turistas, que se entiendan sus motivaciones, sus satisfacciones e insatisfacciones.

Desde hace años se explora la reacción psicológica del visitante desde distintos puntos de vista. La ciencia geográfica analiza el territorio, su estado actual y funcionamiento ante determinados hechos espaciales, entre ellos la masificación-saturación de un destino turístico. Masificación y saturación no es una cuestión estrictamente cuantitativa.

En este estudio se pretende diagnosticar la opinión del individuo ante la carga existente, su percepción de la masificación y su reacción ante ella, estableciendo un modelo de capacidad de carga social percibida por el turista.

La capacidad de carga social percibida por los turistas puede ser definida como el umbral de saturación tras el cual los turistas buscan destinos alternativos. Los diferentes estudios llevados a cabo sobre la capacidad de carga percibida por los turistas se fundamentan en la siguiente idea: el grado de concentración de un destino turístico se relaciona con la calidad de la experiencia turística. Consecuentemente, es lógico pensar que si elevamos la intensidad del uso de un territorio, el nivel de satisfacción puede disminuir.

No obstante, ese nivel de satisfacción no es el resultado de un solo factor (la masificación) sino de múltiples aspectos que debemos tener en cuenta: 
- La calidad visual de un paisaje.

- Las expectativas establecidas.

- La acogida por parte de los residentes.

- Las actividades realizadas

- Otras variables sociales y personales propias del turista.

En resumen, hay que tener en cuenta que en la masificación interviene conceptos, actitudes y experiencias subjetivas que dificultan la individualización de estos factores en un análisis de conjunto.

\subsection{Fuentes de Información}

Para conocer algunos de los aspectos anteriormente planteados, se hizo necesario el contar con una fuente de información específica. Para ello se diseñó una encuesta y se creó un pequeño equipo para realizarla. Los datos básicos de la encuesta se desglosan a continuación.

\begin{tabular}{|l|c|c|}
\hline & FRECUENCIA & \% \\
\hline TEMPORADA ALTA & 275 & 66,6 \\
\hline TEMPORADA BAJA & 125 & 33,4 \\
\hline TOTAL DE LA MUESTRA & 400 & 100,0 \\
\hline
\end{tabular}

- Nivel de confianza $=95 \%$ para toda la muestra y temporadas.

- Error de muestreo $=+/-3,35 \%$ para el total de la muestra

- Recogidas de muestras en puntos estratégicos: Plaza del Obradoiro, Alameda, Plaza del Toral, Dársena Xoán XXIII y Puerta del Camino.

- Encuestas en castellano e inglés.

La información proporcionada se ha combinado, lógicamente, con otras fuentes como el Observatorio Turístico de Santiago de Compostela, los boletines de Turismo de Santiago y los datos estadísticos aportados por el INE y Turgalicia. La explotación de la información proporcionada por la encuesta se realiza a continuación, en combinación con otras fuentes. 
3.4. Características básicas de la demanda turística de Santiago de Compostela

A. Las principales características de la demanda

- Importante peso del mercado nacional (63\%), especialmente en temporada alta. Los principales focos emisores son Madrid, Andalucía, Cataluña y Valencia.

- El turista predominante tiene una edad madura (44,6 años). Los jóvenes tienen mayor importancia en verano, mientras que los más mayores se concentran en la temporada baja.

- Dentro de los turistas extranjeros predominan los franceses, alemanes, portugueses e italianos, que suponen casi el 50\% del total.

- El nivel formativo tanto de los nacionales como de los extranjeros es muy elevado, destacando el elevado porcentaje de visitantes universitarios.

- La oferta hotelera en el 2004 fue de 6.393 plazas, con un porcentaje elevado de hoteles de elevada categoría (4 hoteles de 5 estrellas). Existe un importante turismo de calidad que utiliza un alojamiento de elevada categoría.

\section{PROCEDENCIA DE LOS TURISTAS EXTRANJEROS ENCUENTADOS (\%)}

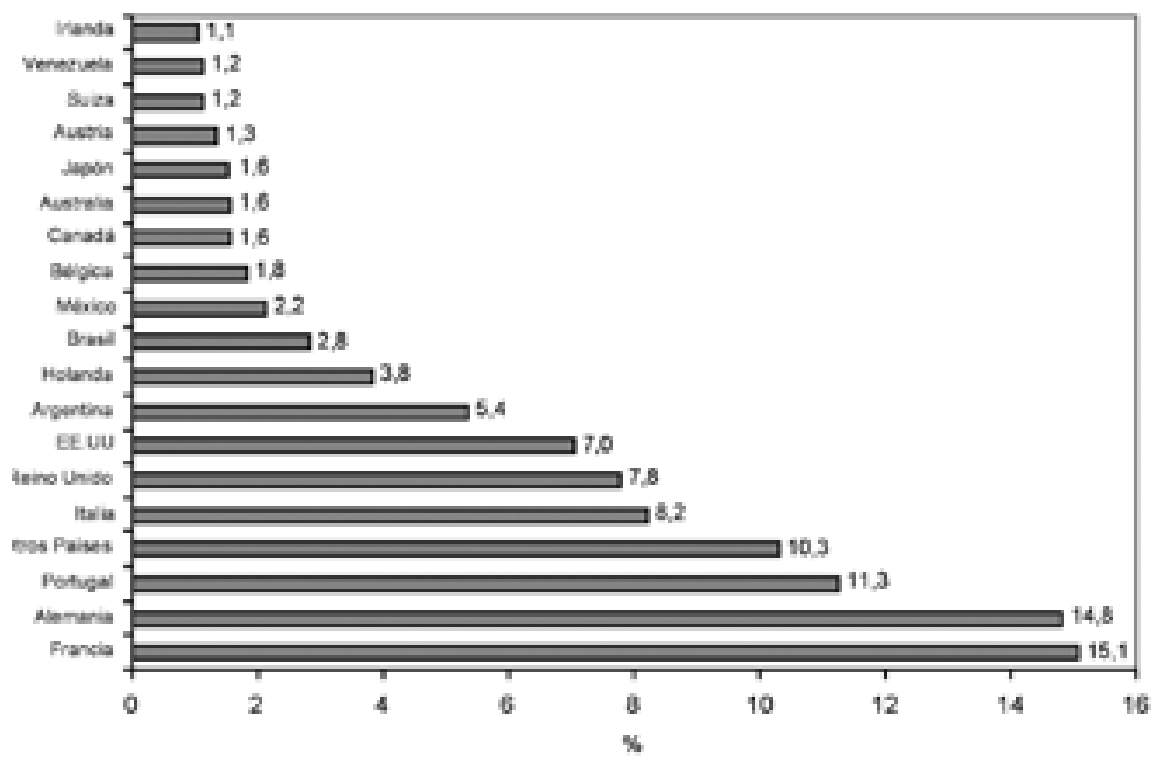


- La tasa de ocupación media en el año 2004 fue del 55,27\%

- La duración media de la estancia es de 2,1 días.

- El número de turistas que se alojaron en hoteles durante 2004 fue de 617.201 y las pernoctaciones fueron de más de 1,3 millones.

- A pesar de identificarse a Santiago de Compostela con destino cultural, la principal motivación que se mantiene es la de ocio y descanso.

- Todas las variables analizadas muestran una clara tendencia al crecimiento: plazas hoteleras, pernoctaciones, turistas, peregrinos, consultas oficinas de turismo, etc.

\section{EVOLUCIÓN DE LA OFERTA DE PLAZAS HOTELERAS}

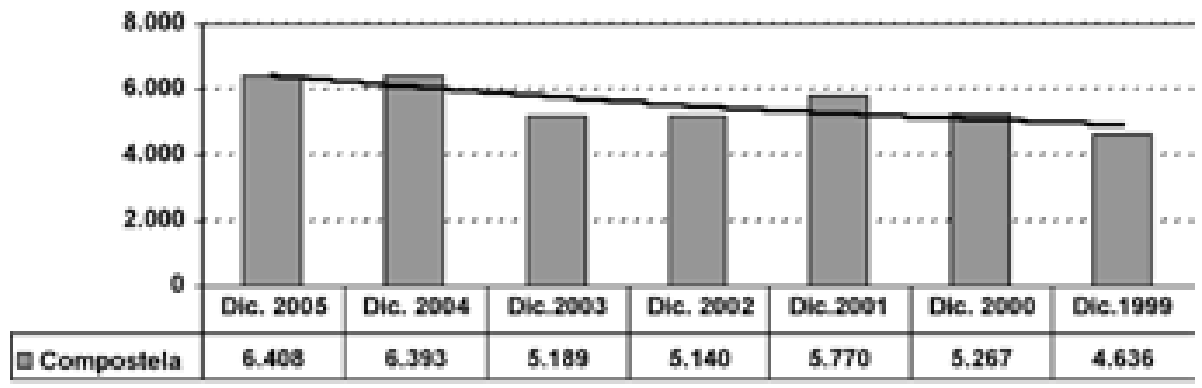

Fuente: INE.

\section{GRADO DE OCUPACIÓN POR PLAZAS TURÍSTICAS HOTELERAS, 2004. SANTIAGO DE COMPOSTELA}

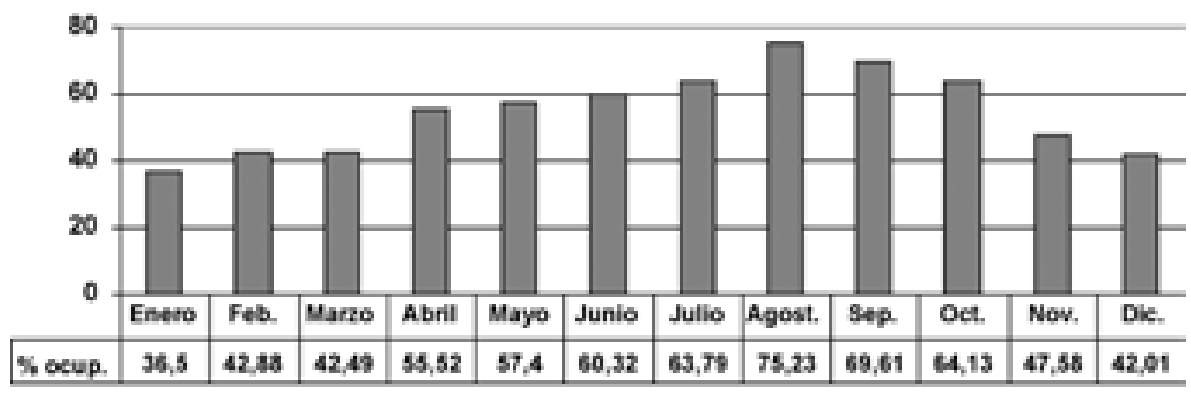

Fuente: INE. 


\section{EVOLUCIÓN DE LAS CONSULTAS EN LAS OFICINAS DE INFOR- MACIÓN TURÍSTICA DEL CONCELLO DE SANTIAGO}

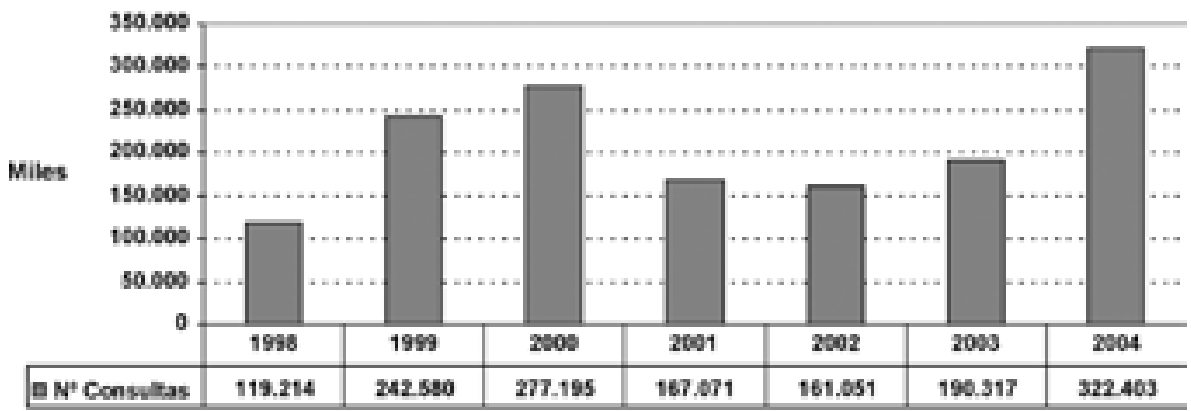

Fuente: Turismo de Santiago.

\section{EVOLUCIÓN DE LA DEMANDA TURÍSTICA EN SANTIAGO DE COMPOSTELA}

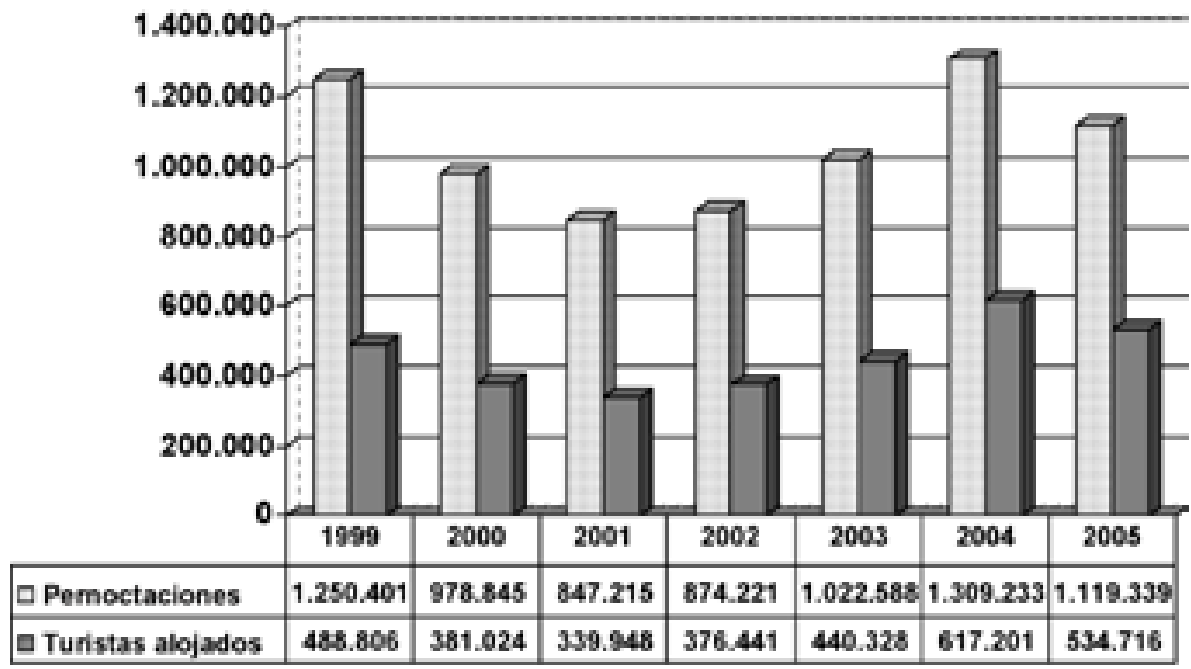

Fuente: INE. Nota: 1999 Año Santo, 2000 Capital Europea de la Cultura. 


\begin{tabular}{|l|c|c|c|c|}
\hline PROCEDENCIA & Temporada Alta & $\begin{array}{c}\text { Temporada } \\
\text { Baja }\end{array}$ & Total Anual & $\begin{array}{c}\text { Edad } \\
\text { (años) }\end{array}$ \\
\hline NACIONAL & $67 \%$ & $33 \%$ & $63 \%$ & 41,8 \\
\hline EXTRANJERO & $33 \%$ & $41 \%$ & $37 \%$ & 47,8 \\
\hline Media de Edad (años) & & & & 44,6 \\
\hline
\end{tabular}

Fuente: Encuesta.

\section{PROCEDENCIA DEL TURISTA NACIONAL}

\begin{tabular}{|l|c|c|c|}
\hline Comunidad de Procedencia & $\%$ & $\begin{array}{c}\text { Comunidad de } \\
\text { Procedencia }\end{array}$ & $\%$ \\
\hline Andalucía & 13,12 & C-León & 7,12 \\
\hline Aragón & 4,14 & Extremadura & 1,52 \\
\hline Asturias & 2,79 & Galicia & 7,10 \\
\hline Baleares & 1,44 & La Rioja & 1,17 \\
\hline Canarias & 2,49 & Madrid & 18,09 \\
\hline Cantabria & 1,46 & Murcia & 2,57 \\
\hline Cataluña & 13,56 & Navarra & 2,23 \\
\hline Ceuta/ Melilla & 0,26 & P. Vasco & 7,00 \\
\hline C-La Mancha & 4,22 & Valencia & 9,69 \\
\hline
\end{tabular}

Fuente: Encuesta

3.5. Características del destino y de la oferta turística de Santiago de Compostela

Las características del destino, tanto las físicas como las sociales, pueden influir en el umbral de la capacidad del destino. Tanto es así, que la demanda valora en su conjunto todas las características, pese a que muchos visitantes diferencien aspectos negativos y positivos. Por ello, es preciso descomponer los distintos factores del destino y que sean los turistas los que opinen. Los aspectos estudiados del destino se han recogido en tres bloques en la encuesta.

- El primero hace referencia a las infraestructuras urbanas.

- El segundo incide en aspectos medioambientales.

- El tercero recoge factores diversos pero que tienen una gran importancia en la capacidad de carga y en la gestión de flujos de visitantes. 
En general, las opiniones obtenidas de las características del destino han sido positivas, (la valoración global de los tres bloques es de 7,66 puntos), aunque se detectan ciertas inquietudes y algunas diferencias temporales. En buena lógica, en temporada alta la carga turística es mayor, incrementándose la sensación de masificación. De hecho, aspectos que se pueden ser valorados negativos en época estival, son percibidos positivamente en temporada baja. Así mismo, hay que señalar que la encuesta se realizó en pleno Año Santo y que deben producirse alteraciones interanuales, que en este momento no es posible analizar.

Observadas las respuestas de los entrevistados se comprueba como hay una valoración bastante positiva de los aspectos relacionados con las infraestructuras (7,50 de puntuación global). La mayor parte de los visitantes se encuentran bastantes satisfechos con los servicios y el mantenimiento de las infraestructuras urbanas de Santiago.

La mejor valoración la proporciona la limpieza de las calles, el estado de conservación de las calles y el mobiliario urbano. Estos aspectos contribuyen a mejorar el paisaje urbano con el que se encuentra el visitante e incide muy positivamente en la calidad de la experiencia turística.

\section{NIVEL DE SATISFACCIÓN RESPECTO A LAS INFRAESTRUCTU- RAS URBANAS Y SU MANTENIMIENTO}

\begin{tabular}{|l|c|c|c|c|c|}
\hline & $\begin{array}{c}\text { Muy } \\
\text { Insatisfecho } \\
(0-3) \%\end{array}$ & $\begin{array}{c}\text { Poco } \\
\text { Satisfecho } \\
(3,1-5) \%\end{array}$ & $\begin{array}{c}\text { Bastante } \\
\text { Satisfecho } \\
(5,1-8) \%\end{array}$ & $\begin{array}{c}\text { Muy } \\
\text { Satisfecho } \\
(8,1-10) \%\end{array}$ & $\begin{array}{c}\text { Puntuación } \\
\text { media }\end{array}$ \\
\hline $\begin{array}{l}\text { Servicios para } \\
\text { discapacitados }\end{array}$ & 8,1 & 11,8 & 50,9 & 29,2 & 7,0 \\
\hline $\begin{array}{l}\text { Limpieza de las } \\
\text { calles }\end{array}$ & 2,1 & 5,6 & 62,1 & 30,2 & 7,8 \\
\hline $\begin{array}{l}\text { Estado de } \\
\text { conservación de las } \\
\text { calles }\end{array}$ & 1,4 & 6,6 & 51,1 & 40,9 & 8,5 \\
\hline $\begin{array}{l}\text { Señalización turística } \\
\text { Facilidad de } \\
\text { aparcamiento }\end{array}$ & 2,3 & 13,5 & 72,6 & 11,6 & 7,9 \\
\hline $\begin{array}{l}\text { Problemas de acceso } \\
\text { a Santiago }\end{array}$ & 10,6 & 11,9 & 45,6 & 31,9 & 6,9 \\
\hline
\end{tabular}




\begin{tabular}{|l|c|c|c|c|c|}
\hline & $\begin{array}{c}\text { Muy } \\
\text { Insatisfecho } \\
(0-3) \%\end{array}$ & $\begin{array}{c}\text { Poco } \\
\text { Satisfecho } \\
(3,1-5) \%\end{array}$ & $\begin{array}{c}\text { Bastante } \\
\text { Satisfecho } \\
(5,1-8) \%\end{array}$ & $\begin{array}{c}\text { Muy } \\
\text { Satisfecho } \\
(8,1-10) \%\end{array}$ & $\begin{array}{c}\text { Puntuación } \\
\text { media }\end{array}$ \\
\hline $\begin{array}{l}\text { Estado de } \\
\text { conservación del } \\
\text { mobiliario urbano }\end{array}$ & 2,3 & 3,7 & 66,2 & 27,8 & 7,7 \\
\hline Media & 6,77 & 10,80 & 56,40 & 26,03 & 7,50 \\
\hline
\end{tabular}

Nota: Los grupos de satisfacción representan un porcentaje sobre el total de las respuestas.

Una mención especial tiene la señalización turística, que recibe una elevada puntuación (el 72,6\% se encuentra bastante satisfecha con ella), aunque el poco impacto visual de la señalítica provoca que no sea percibida por algunos visitantes. La señalización turística juega un papel fundamental para la gestión de los flujos turísticos y sobre todo, para canalizar los grupos y los visitantes turísticos hacia otras zonas menos congestionadas.

Se perciben ciertos problemas con los aparcamientos, (grave dificultad para algunos visitantes que intentan acercarse directamente a un casco histórico fundamentalmente peatonal) y algunos problemas de tráfico y señalización en las entradas de la ciudad. En general, la distribución urbana de los accesos provoca cierta congestión en determinados puntos de la ciudad, en especial en algunas zonas periféricas del casco histórico, como es la Praza de Galicia y el nudo de tráfico frente a la Alameda. La Dársena Xoán XIII presenta pocos problemas de tráfico.

La escasez de plazas de estacionamiento obliga a una reflexión sobre la necesidad de construir más plazas de aparcamiento, aunque algunas actuaciones vienen a aliviar ligeramente la situación (Parking de la Praza Roxa en el Ensanche). De todos modos, el constante incremento de actividad en toda la zona (comercial, administrativa, etc.) y de los visitantes turísticos, provocará un incremento de la demanda de aparcamiento. 


\section{NIVEL DE SATISFACCIÓN RESPECTO A LOS ASPECTOS AMBIENTALES}

\begin{tabular}{|l|c|c|c|c|c|}
\hline & $\begin{array}{c}\text { Muy } \\
\text { Insatisfecho } \\
(0-3) \%\end{array}$ & $\begin{array}{c}\text { Poco } \\
\text { Satisfecho } \\
(3,1-5) \%\end{array}$ & $\begin{array}{c}\text { Bastante } \\
\text { Satisfecho } \\
(5,1-8) \%\end{array}$ & $\begin{array}{c}\text { Muy } \\
\text { Satisfecho } \\
(8,1-10) \%\end{array}$ & $\begin{array}{c}\text { Puntuación } \\
\text { media }\end{array}$ \\
\hline $\begin{array}{l}\text { Conservación de los } \\
\text { espacios verdes }\end{array}$ & 1,2 & 4,5 & 13,9 & 80,4 & 8,5 \\
\hline $\begin{array}{l}\text { Tranquilidad/ } \\
\text { ausencia de ruidos }\end{array}$ & 5,6 & 6,9 & 75,6 & 11,9 & 6,9 \\
\hline $\begin{array}{l}\text { Valoración general } \\
\text { del clima }\end{array}$ & 11,9 & 12,8 & 72,1 & 3,2 & 7,1 \\
\hline Media & 6,23 & 8,07 & 53,87 & 31,88 & 7,53 \\
\hline
\end{tabular}

Nota: Los grupos de satisfacción representan un porcentaje sobre el total de las respuestas.

En relación con la valoración de los aspectos ambientales hay que poner de relieve que estos son muy bien valorados (7,53 puntos), en especial, los espacios verdes que reciben una puntuación muy elevada $(8,5)$.

Los parques y jardines de la ciudad son uno de los factores que proporcionan identidad a Santiago de Compostela. Juegan un papel muy importante para descongestionar, crear perspectivas y ampliar la capacidad de carga. Los parques que rodean el casco histórico crean unas visuales de singular belleza que son valoradas muy positivamente por los visitantes.

El ruido es un problema que sin llegar a ser uno de los más llamativos es, de todos modos, señalado por los turistas. Esta situación se hace evidente en algunos puntos del casco histórico. Es uno de los factores, que de forma general, influye más negativamente en la reducción de la calidad de la experiencia turística.

En contra de lo que a priori puede parecer el clima no es un gran obstáculo medioambiental. Si bien para algunos es un aspecto negativo, la mayor parte de los turistas lo asumen como algo consustancial a la ciudad y no influye en nivel de satisfacción de la experiencia turística. Para los turistas que llegan en época estival desde el centro y sur de la Península Ibérica, el clima lluvioso y suave puede ser un elemento positivo en la experiencia turística.

En el último bloque, se valoran aspectos diversos relacionados estrechamente con el destino, como son algunos recursos patrimoniales (catedral e iglesias), oferta e infraestructura turística básica (alojamiento, restaurantes, museos, oficinas de turismo, comercios, etc.) y otros factores que juegan un 
papel esencial en la calidad del destino y su percepción (seguridad, trato y autenticidad).

$\mathrm{Al}$ igual que el análisis de los anteriores aspectos se puede decir que el grado de satisfacción es bastante elevado y que predomina la franja de los que están bastante satisfechos. La puntuación global es de 7,94 puntos.

Lo que recibe una mayor valoración son las oficinas de turismo, los parques y jardines, la seguridad, la amabilidad y el trato y la autenticidad del destino. Son estos factores los que proporcionan una mayor calidad a la experiencia turística, a pesar de que pueda haber problemas puntuales. Mientras se mantengan estos factores con una elevada valoración, la visita a Santiago será satisfactoria.

Los problemas se detectan en ciertos recursos y servicios, que en el Año Santo de 2004 han presentado algunas deficiencias. Además, hay que señalar que estos son evidentes en temporada alta, mientras que en temporada baja son poco patentes. Es decir, el alojamiento y la restauración, el transporte público, las compras en comercios y la visita a la catedral.

Tal vez el más patente y llamativo sea la visita a la Catedral, rito habitual e ineludible de cualquier visita a Santiago de Compostela. Esta visita refleja ciertas insatisfacciones, ya que la catedral en ciertas fechas está absolutamente abarrotada. Esto, desde luego, ha restado buena parte de la calidad de la experiencia, y es uno de los aspectos en los que más detenidamente habría que trabajar.

Aunque en el año 2004 se han limitado las visitas a ciertas horas y se ha controlado interna y externamente las colas y recorridos, el ritmo de visitas y la presión sobre el patrimonio es evidente. Se hace necesario diseñar algunas estrategias de gestión (cobro simbólico de entrada, limitar el aforo de entrada, etc.) para preservar este patrimonio único.

Además, la Catedral es la pieza del casco histórico que más sufre el excursionismo y la presión física. A pesar de ello, el nivel de satisfacción general es elevado, así como su puntuación.

NIVEL DE SATISFACCIÓN RESPECTO A LOS SIGUIENTES ASPECTOS

\begin{tabular}{|l|c|c|c|c|c|}
\hline & $\begin{array}{c}\text { Muy } \\
\text { Insatisfecho } \\
(0-3) \%\end{array}$ & $\begin{array}{c}\text { Poco } \\
\text { Satisfecho } \\
(3,1-5) \%\end{array}$ & $\begin{array}{c}\text { Bastante } \\
\text { Satisfecho } \\
(5,1-8) \%\end{array}$ & $\begin{array}{c}\text { Muy } \\
\text { Satisfecho } \\
(8,1-10) \%\end{array}$ & $\begin{array}{c}\text { Puntuación } \\
\text { media }\end{array}$ \\
\hline Catedral & 8,5 & 9,8 & 33,5 & 48,2 & 7,8 \\
\hline Museos & 2,3 & 5,6 & 62,1 & 30 & 7,9 \\
\hline Iglesias & 1,5 & 6,6 & 51,1 & 40,8 & 8,1 \\
\hline
\end{tabular}




\begin{tabular}{|l|c|c|c|c|c|}
\hline & $\begin{array}{c}\text { Muy } \\
\text { Insatisfecho } \\
(0-3) \%\end{array}$ & $\begin{array}{c}\text { Poco } \\
\text { Satisfecho } \\
(3,1-5) \%\end{array}$ & $\begin{array}{c}\text { Bastante } \\
\text { Satisfecho } \\
(5,1-8) \%\end{array}$ & $\begin{array}{c}\text { Muy } \\
\text { Satisfecho } \\
(8,1-10) \%\end{array}$ & $\begin{array}{c}\text { Puntuación } \\
\text { media }\end{array}$ \\
\hline Comercios & 11,3 & 10,5 & 64,6 & 13,6 & 7,6 \\
\hline $\begin{array}{l}\text { Transporte público } \\
\text { urbano }\end{array}$ & 9,8 & 14,5 & 62,1 & 13,6 & 7,7 \\
\hline Taxis & 10,1 & 11,2 & 51,8 & 26,9 & 7,6 \\
\hline $\begin{array}{l}\text { Restaurantes y } \\
\text { cafeterías }\end{array}$ & 9,2 & 16,5 & 55,2 & 19,1 & 7,4 \\
\hline Oficinas de turismo & 3,2 & 2,1 & 86,2 & 8,5 & 8,3 \\
\hline Alojamiento & 9,8 & 9 & 54,1 & 27,1 & 7,9 \\
\hline Parques y jardines & 0,9 & 4,3 & 75,7 & 19,1 & 8,5 \\
\hline Seguridad & 1,9 & 5,8 & 56,5 & 35,8 & 8,4 \\
\hline Amabilidad y trato & 4,5 & 2,3 & 62,6 & 30,6 & 8,4 \\
\hline $\begin{array}{l}\text { Autenticidad del } \\
\text { destino }\end{array}$ & 5,2 & 14,2 & 64,3 & 16,3 & 8,0 \\
\hline Media & 6,02 & 8,65 & 59,68 & 25,35 & 7,94 \\
\hline
\end{tabular}

Nota: Los grupos de satisfacción representan un porcentaje sobre el total de las respuestas.

Se observa una importante falta de profesionalidad entre algunos empresarios que repercute negativamente en la experiencia global del turista. Un matiz muy parecido presenta los descontentos en el comercio. A pesar de ello, el porcentaje más importante de los turistas tiene una impresión muy positiva respecto a estos aspectos.

También se localizan ciertos problemas en los transportes públicos (autobuses y taxis). Estos están ligados a las tarifas, falta de amabilidad y tiempo de espera.

Por último, señalar que empieza a detectarse ciertos problemas en la autenticidad del destino turístico, aspecto que puede ser un gran problema para el futuro crecimiento y cualificación de la ciudad de Santiago de Compostela. El problema de la musealización de las ciudades históricas no es nuevo, ha despoblado ciudades como Venecia. 


\section{INDICADOR DE LA CAPACIDAD DE CARGASOCIAL PERCIBIDA POR LOS TURISTAS}

El indicador elegido para medir la capacidad de carga social es la percepción de la masificación. A partir de esta cuantificación se puede valorar la opinión que tienen los turistas sobre la carga actual.

Debemos saber, tal y como han demostrado diversos autores (Shelby, 1986) que las respuestas sobre la variable masificación no son siempre sinceras. Las personas pueden ser reacias a decir que un área está abarrotada porque la masificación es una característica indeseable en una escena de recreación.

El término masificación lleva implícito un juicio negativo, ya que este término implica que el número de personas en un lugar es demasiado, lo que puede representar una experiencia desagradable.

PERCEPCIÓN DE LA MASIFICACIÓN (\%)

\begin{tabular}{|c|c|c|}
\hline & SI & NO \\
\hline Temporada Alta & 19,6 & 80,4 \\
\hline Temporada Baja & 7,4 & 92,6 \\
\hline Media & 13,5 & 86,5 \\
\hline
\end{tabular}

La masificación en Santiago de Compostela es percibida más claramente en temporada alta, suponiendo casi un $20 \%$ de los turistas y visitantes, disminuyendo ostensiblemente en temporada baja. La media se sitúa en 13,5\%.

Los lugares citados en los que percibían la masificación se repiten. En primer lugar y forma destacada, señalan que la Catedral $(58,5 \%)$, seguido de los restaurantes $(16,5 \%)$ y, en tercer lugar algunas calles (Rúa do Franco, etc.).

Si bien casi el $85 \%$ está bastante y muy satisfecho de la visita a Santiago y puntúan a la ciudad con 7,66, existe un segmento de casi un $15 \%$ (incluye muy insatisfechos y poco satisfechos) que no está muy contento con la visita y que puede que no vuelva y que difundan imágenes negativas de la ciudad. Es sobre estos aspectos sobre los que hay que trabajar. Esta afirmación está, así mismo, relacionada con la percepción de masificación, que sin ser muy elevada, comienza a producirse. 
VALORACIONES MEDIAS

\begin{tabular}{|l|c|c|c|c|c|}
\hline & $\begin{array}{c}\text { Muy } \\
\text { Insatisfecho } \\
(0-3) \%\end{array}$ & $\begin{array}{c}\text { Poco } \\
\text { Satisfecho } \\
(3,1-5) \%\end{array}$ & $\begin{array}{c}\text { Bastante } \\
\text { Satisfecho } \\
(5,1-8) \%\end{array}$ & $\begin{array}{c}\text { Muy } \\
\text { Satisfecho } \\
(8,1-10) \%\end{array}$ & $\begin{array}{c}\text { Puntuación } \\
\text { media }\end{array}$ \\
\hline $\begin{array}{l}\text { Media Infraestructuras } \\
\text { urbanas y } \\
\text { mantenimiento }\end{array}$ & 6,77 & 10,80 & 56,40 & 26,03 & 7,50 \\
\hline $\begin{array}{l}\text { Media de aspectos } \\
\text { Ambientales }\end{array}$ & 6,23 & 8,07 & 53,87 & 31,88 & 7,53 \\
\hline $\begin{array}{l}\text { Media Aspectos } \\
\text { turísticos diversos }\end{array}$ & 6,02 & 8,65 & 59,68 & 25,35 & 7,94 \\
\hline Media global & 6,34 & 9,17 & 56,65 & 27,75 & 7,66 \\
\hline
\end{tabular}

Las ciudades culturales viven siempre en un inestable equilibrio entre sus visitantes que vienen a admirar su pasado y la presión que ejercen en ese proceso y que puede desembocar en la desaparición del elemento de atracción.

También es cierto que la masificación desde el lado de la demanda, tiene muchas y diversas lecturas. Si hubiera sido posible, a priori, distinguir el tipo de turista encuestado, observaríamos que el excursionista tiene un umbral de carga más alto que turista convencional o el peregrino.

Si entráramos a distinguir los factores psicosociales que intervienen en la percepción de la masificación, se hubiese complicado en exceso el fin último del trabajo, que es analizar aspectos de la oferta y de la demanda de Santiago, detectar ciertos problemas de congestión y trazar algunas recomendaciones.

En resumen, hay que tener en cuenta que un $13 \%$ de los turistas y visitantes perciben masificación y para un $15 \%$ no se alcanzan los niveles de satisfacción que a priori éste había trazado. Dentro de este 15\%, la situación grave se centra en un $6 \%$.

\section{CONCLUSIONES}

- El año 2004, fecha de realización de la encuesta, coincidió con la celebración del Año Santo, lo que dio lugar a que las cifras relacionadas con el turismo se multiplicasen. A la vez fue un momento ideal para la elaboración de este estudio. Los grandes datos avalan la presencia de unos tres millones de visitantes y excursionistas y más de un millón de turistas. El aeropuerto de Lavacolla recibió en el 2004 cerca de 1,6 millones de pasajeros. 
- El Año Santo de 2004 ha supuesto una fuerte tensión sobre la capacidad de carga turística, a pesar de la tradicional adaptabilidad de la ciudad a estas congestiones. Tensión en lo físico y en lo social. En el primer aspecto, la ciudad ha tenido que dar cabida y ampliar sus servicios a millones de personas, a pesar de ser una población con tamaño reducido. Si bien es verdad que la ciudad cuenta con "savoir faire" tradicional, no es menos que se siguen produciendo presiones por encima de lo recomendado. Un ejemplo singular es la protección del Pórtico de la Gloria en la Catedral. En lo social, hay que llamar la atención sobre el notable grado de vitalidad que muestra el centro histórico, a pesar de las enormes presiones a las que se ve sometido sus habitantes, sobre todo, en comparación con otras Ciudades Patrimonio de España (Toledo, Ávila, etc.). Esta situación no quiere decir que no se presenten ciertas advertencias que se pueden observar a través de sutiles indicadores: desaparición de las tiendas tradicionales de comestibles y su sustitución por tiendas de venta de recuerdos. La existencia de un notable porcentaje de población joven en el casco no excluye a este territorio de los mismos males que otras ciudades, ni tampoco significan que puedan absorber con alegría la presión turística.

- Por otro lado, la visión y la experiencia turística del visitante sobre el destino Santiago de Compostela es términos generales bastante positiva: un 7,66 sobre 10. El foráneo destaca una serie de elementos que proporciona calidad a su visita: la información turística, los parques y jardines, el patrimonio, la amabilidad y la autenticidad del destino. Este último factor tiene gran importancia, pues supone que la ciudad está lejos del proceso de museolización que han sufrido otras ciudades históricas, que se han convertido en autentico decorados de piedra sin vida. La calidad de la experiencia destaca una mezcla de tangibles (jardines, rúas, iglesias, etc.) e intangibles (autenticidad, amabilidad).

- Esta situación no debería llevar a la autocomplacencia a los gestores de un destino, pues los turistas, los propios clientes, señalan la presencia de deficiencias (problemas en algunos alojamientos, precios excesivos en restaurantes, etc.) y un $13 \%$ de los turistas y visitantes perciben masificación.

- Un aspecto fundamental en relación con las ideas anteriormente señaladas es la correcta gestión de los flujos de visitantes. Este hecho es el que permitirá incrementar la calidad de la experiencia turística, aumentar el umbral de capacidad y disminuir la percepción de masificación. Por ello es preciso, en primer lugar, potenciar el conocimiento de otros espacios de la ciudad. Hay que conseguir despegar al turista y visitante del escaso territorio sobre el que se mueve. A modo de 
ejemplo, en Santiago de Compostela sería de gran interés poder dirigir los flujos turísticos hacia otras zonas de gran valor patrimonial y ambiental como es el conjunto de Santo Domingos de Bonaval. Hay que recrear la misma vida que se encuentran en las rúas centrales del casco (dinamización comercial) y colocar elementos de mobiliario urbano que inviten al turista a perderse hacia esas calles. Este área tiene una presión muy escasa y posee un gran potencial de recepción de los turistas, de hecho cuenta con los mayores museos de la ciudad, además de un espacio verde de singular belleza.

- Uno de los puntos señalados como espacialmente congestionado o masificado es la Catedral. El papel que juega como hito urbano unido al deseo unánime de todo turista de entrar en la catedral y realizar el ritual correspondiente provoca una fuerte congestión. Esta se hace evidente en temporada alta y en especial en Año Santo. Esta situación está provocando un descenso evidente en la calidad de la experiencia turística e incluso está afectando al propio patrimonio de la Catedral.

- Aunque la restricción y el cobro de entrada es una herramienta dificultosa en una catedral de peregrinación, es preciso avanzar en las medidas tomadas este año (restricción de las visitas turísticas, de los horarios de entrada, protección del Pórtico de la Gloría, etc., e incluso pensar en cobrar una entrada simbólica que sirva de cedazo ante posibles avalanchas de visitantes. Hay que pensar en mejorar una experiencia que debe tener un cierto recogimiento, a la vez que proteger el propio edificio.

- En la idea de extender la visita turística más allá del espacio restringido en torno a la catedral y calles aledañas, hay que tener en cuenta el número importante de iglesias, monasterios, conventos y ermitas que puebla toda la ciudad. Es una ciudad que tiene un gran pasado religioso. Esta amplio patrimonio es un gran recurso que permitirá la creación de nuevas rutas y espacios de interpretación del legado cultural. A modo de ejemplo será de gran interés la creación de una ruta que una la Colegiata de Sar con el gran complejo de la Ciudad de la Cultura.

- Santiago de Compostela dispone de un extenso término municipal (casi $250 \mathrm{~km} 2$ ). Tiene un amplio espacio rural que apenas está explotado. Hay un importante legado patrimonial (pazos, puentes, molinos, ermitas, etc.) y un paisaje que tiene unas enormes posibilidades. El turismo rural apenas ha despuntado. Se pueden realizar gran número de rutas por los montes cercanos (Monte Pedroso) e incluso por las riberas de los ríos que entran en la propia ciudad (Ribera del Sarela, Carballera de San Lorenzo). 
- Otra línea necesaria para disminuir la presión sobre los recursos y espacios turísticos, es la creación de nuevos productos turísticos. Es necesario la diversificación de la oferta actual, teniendo en cuenta que se dispone de unos recursos bastante amplios y diversos. Algunas actuaciones recientes han ido en esta línea, como es la visita al patrimonio universitario, una de las joyas de Santiago. Queda pendiente el desarrollo de la artesanía, de la gastronomía, etc. En resumen, el incremento del umbral de la capacidad de carga turística estará en relación con la creación de nuevas actividades y productos turísticos, no masivos y cualificados. 


\section{BIBILIOGRAFÍA}

BALLART HERNÁNDEZ, J.; JUAN I TRESSERRAS J. (2005): Gestión del patrimonio cultural, Ariel Patrimonio, Barcelona.

BUCKLEY, RALF (1999): “An ecological perspective on carrying capacity”, Annals of Tourism Research 26.

BORG, J. VAN DER; GOTTI, G. (1995): Tourism and cities of art: the impact of tourism and visitors flow managemet in Aix-an-Provence, Amsterdam, Bruges, University of Venice-Ciset.

CONCELLO DE SANTIAGO DE COMPOSTELA (1999-2004): Anuario estadístico de Santiago de Compostela.

DE LA CALLE V.AQUERO, M. (2002): La ciudad histórica como destino turístico, Ariel Turismo, Barcelona.

GARCÍA DOCAMPO, M. (1998): Visitantes y peregrinos de Compostela. VI Congreso Nacional de Sociología, Inédito, A Coruña.

GARCIA HERNANDEZ, M (2000): "Los flujos de visitantes y la capacidad de acogida turística del conjunto monumental de la Alhambra y Generalife", Cuadernos de la Alhambra.

GARCIA HERNANDEZ, M (2001): Turismo y conjuntos monumentales: capacidad de acogida turística y gestión de flujos de visitantes, Tesis doctoral inédita. Dpto. Geografía Humana. Universidad Complutenses de Madrid.

GARCIA MENENDEZ, L (1986): "La actividad turística en relación con la capacidad de acogida del territorio en la Comunidad Valenciana" en Ecología, economía y turismo en el Mediterráneo, Ayuntamiento de Benidorm y Universidad de Alicante. Alicante.

GLASSON, J; GODFREY, K y GOODEY, B. (1995): Towards Visitor Impact Management. Visitor impacts, carrying capacity and management reponses in Europe's historic towns and cities, Edit Avebury. Aldershot.

GRAEFE, A. R. ; KUSS, F. R. y VASKE, J.J. (1990): Visitor Impact Management. The planning framework, Vol II. National Parks and Conservation Association. Washington, D.C.

INSTITUTO GALEGO DE ESTADÍSTICA (1999-2004): Enquisa continúa de ocupación hoteleira de Galicia, Santiago de Compostela.

INSTITUTO NACIONAL DE ESTADÍSTICA (1999-2004): Encuesta de ocupación hotelera, Madrid.

LINDBERG, K.; McCOOL, S. y STANKEY, G (1997): "Rethinking carrying capacity", Annals of Tourism Research 24-2, 461-46.

MARTÍN GIL, F. (1997): "Gestión del turismo en ciudades con patrimonio cultural", IV Congreso de la AECIT Turismo, Ciudad y Patrimonio Cultural en el sur de Europa e Iberoamérica, inédito, San Sebastián.

OBSERVATORIO TURÍSTICO DE SANTIAGO DE COMPOSTELA (2005): Enquisa de Demanda de Santiago de Compostela, Universidade de Santiago de Compostela.

SALEEM, N. (1994): "The destination capacity index: a measure to determine the tourist carrying capacity" en Tourism- State of the Art, Edt John \& Sons. Chichester 
SHELBY, B. B. y HEBERLEIN, T. A. (1986): Carrying capacity in recreation settings, Oregon State University Press. Corvallis.

TROITIÑO VINUESA, M.A. (1998): "Turismo y desarrollo sostenible en ciudades históricas", Ería n ${ }^{\circ}$ 47. Monográfico dedicado al turismo en las ciudades históricas, pags. 211-228.

TURISMO DE SANTIAGO DE COMPOSTELA (2003-04): Boletín de Información Turística, Observatorio Turístico, $\mathrm{n}^{\mathrm{o}} 1-5$, Santiago de Compostela. 